\title{
SISTEMA PENITENCIÁRIO BRASILEIRO E O ENFRENTAMENTO À COVID-19: ANÁLISE PROCESSUAL DA DECISÃO MONOCRÁTICA PROFERIDA NO HC 570.440/DF
}

\author{
Sabrina Silva Moreira \\ Raquel Santana Santos Vargas Duplat \\ Lucas Solto Meira \\ José Carlos Melo Miranda
}

(STJ - HC 570.440 DF 2020/0079174-0, Relator: Ministro Antonio Saldanha Palheiro, Data de Publicação: DJE 06/04/2020)

O Habeas Corpus no 570.440/DF trata-se de uma ação com pedido liminar impetrada pela Defensoria Pública da União (DPU) perante o Superior Tribunal de Justiça (STJ), em favor de todas as pessoas já presas e que forem presas, que estejam nos grupos de risco da Covid-19. Seu principal intento esteve na contenção da pandemia no âmbito dos presídios e, portanto, objetivou-se assegurar os direitos dos encarcerados. Assim, são elencados, enquanto autoridades coatoras, todos os Juízos Federais e Estaduais de primeira e segunda instância. Ressalta-se, ainda, que o órgão de Defesa já havia impetrado, na origem, ante o Tribunal Regional Federal da $3^{\circ}$ Região, o Habeas Corpus Coletivo $\mathrm{n}^{\circ} 5006312$ com o mesmo objeto, sendo o pleito liminar indeferido pelo Tribunal a quo.

Conforme leciona José Afonso da Silva (2002), a Emenda Constitucional de 1926 restringiu o cabimento do HC à proteção da liberdade de locomoção, sendo assim, ele visa tutelar a liberdade de ir, vir e permanecer, nos termos do artigo 5º inciso LXVIII, da Constituição da República Federativa do Brasil de 1988․ Nesse sentido, o presente writ possui caráter repressivo, uma vez que tem como pacientes indivíduos encarcerados, e também preventivo, tendo em vista que também fora postulado em favor daqueles que, porventura, viessem a ser presos. Por fim, igualmente é coletivo, em razão de tutelar o direito de indivíduos que estão inseridos na mesma circunstância fática - ou seja, pertencer aos grupos de risco da Covid-19 -, visando, portanto, cessar ou evitar a coação à liberdade de locomoção no âmbito dos presídios, facultando a possibilidade de prisão domiciliar, dentre outras benesses para, consequentemente, conter a contaminação pelo vírus.

Desta forma, cumpre destacar que, ao decidir, o Ministro Relator Antônio Saldanha Palheiro, primariamente, pontuou o objeto da irresignação firmado pela Defensoria Pública da União, a qual elenca, ao longo da impetração, as razões que visam assegurar a legalidade e o cabimento da ação de Habeas Corpus coletivo na situação provocada pela pandemia da Covid-19. De acordo com a impetrante, a ação (i)"tem como escopo o estabelecimento de 'standards' mínimos uniformes de aplicação obrigatória pelos Juízos Federais e

${ }^{1} \mathrm{O}$ HC é uma ação constitucional que está prevista no artigo $5^{\circ}$, inciso LXVIII, da CRFB/88: “conceder-se-á Habeas Corpus sempre que alguém sofrer ou se achar ameaçado de sofrer violência ou coação em sua liberdade de locomoção, por ilegalidade ou abuso de poder". 
Estaduais, de primeira e segunda instância"”, e prossegue, ressaltando que (ii) "no desiderato de que sejam feitas, por estes (todos os coatores), as análises necessárias a conter a pandemia pela Covid-19 no âmbito das penitenciárias nacionais"2.

Em seguida, o órgão de Defesa demonstra suas pretensões dizendo que não anseia, com a impetração do remédio constitucional em questão, ater-se à legalidade de cada uma das prisões na oportunidade em que foram decretadas, mas, sim, fundamenta o seu pedido com base na ADPF 347 do Supremo Tribunal Federal (STF), a qual reconheceu o estado de coisas inconstitucional que viceja no sistema carcerário brasileiro. A argumentação utilizada pela DPU é no sentido de ser evidente que a pandemia de uma doença respiratória no âmbito do sistema carcerário brasileiro, o qual, visivelmente, possui indivíduos de saúde debilitada, em razão da condição nefasta em que se encontram, o que 'tem o potencial de atingir praticamente todos os presos do país, amontoados em cadeias superlotadas, sem ventilação adequada e sem as mínimas condições de higiene para a prevenção da doença', acarretando, por certo, um absurdo número de mortes entre os encarcerados ${ }^{3}$.

Isto posto, em decisão monocrática, coube ao Sr. Ministro Relator decidir pelo indeferimento liminar do Habeas Corpus firmando-se nos seguintes argumentos: (i) entendimento firmado pela Corte Superior de Justiça, segundo o qual, o Habeas Corpus coletivo não é cabido, porque a competência para o julgamento desse remédio no Superior Tribunal de Justiça deve ser firmada em razão da execução de cada preso conforme entendimento firmado no $\mathrm{AgRg}$ no $\mathrm{HC} \mathrm{n}^{\circ} 269.265 / \mathrm{SP}^{4}$; (ii) seguindo a mesma linha de intelecção da Corte Regional, que indeferiu o pedido liminar anteriormente, reconhece dificuldade de apreciação do pedido liminar, visto que seria decidido "genericamente sem o conhecimento de causa quanto à realidade subjacente de cada situação específica" e sequer sabe-se ao certo quais seriam os juízes responsáveis por eventual abuso ou desvio de poder, requisitos para que se impetre um Habeas Corpus. Esse fundamento encontra-se alinhado com a Recomendação 62 do Conselho Nacional de Justiça (CNJ); (iii) a não superação do enunciado 691 da Súmula do Supremo Tribunal Federal. O Superior Tribunal de Justiça possui Jurisprudência firmada de que não cabe Habeas Corpus impetrado ante decisão que indefere liminar, a não ser que fique demonstrada flagrante ilegalidade (enunciado da Súmula 691 do STF); (iv) impedimento da Corte em analisar o alegado constrangimento ilegal, sob pena de incorrer em indevida supressão de instância e de incidir em patente desprestígio às instâncias ordinárias.

Em primeira análise, destaca-se a importância do objeto discutido por via de Habeas Corpus coletivo impetrado pela Defensoria Pública da União. A Covid-19 e sua alta taxa de transmissão, que levaram o mundo à uma pandemia, poderiam acarretar danos irreversíveis para o Sistema Prisional Brasileiro e seus componentes - funcionários e internos. Dessa forma, era, à época de início da pandemia, legítimo que a problemática chegasse ao Poder Judiciário, principalmente ao se considerar o declarado Estado de Coisas Inconstitucional no sistema carcerário brasileiro (ADPF 347 do Supremo Tribunal Federal). Desconsiderar os

${ }^{2}$ (STJ - HC 570.440 DF 2020/0079174-0, Relator: Ministro Antonio Saldanha Palheiro, Data de Publicação: DJE 06/04/2020).

${ }^{3}$ Ibidem.

${ }^{4}$ (AgRg no HC n. 269.265/SP, Relatora: Ministra Maria Thereza de Assis Moura, Sexta Turma, Data de Publicação: DJe 10/06/2013). 
fatores que levam as prisões a serem lugares de maior vulnerabilidade a qualquer doença de caráter infeccioso - e não só a Covid-19, como dito pela DPU na ação impetrada - seria “transformar a prisão em pena capital".

À vista disso, a conversão ou relaxamento das prisões de pessoas que integram o grupo de risco da doença causada pelo Sars-CoV-2 (popularmente conhecido como coronavírus) de maneira coletiva, partindo do pretexto de defesa da saúde e vida destes, também seria motivo de contrariedades. Haveria de se considerar o princípio da individualização da pena, a fim de que esta não se distancie da sua função. Contudo, não foi estabelecida, pela impetrante, nenhuma perspectiva de como isso poderia ser realizado pelos Juízos competentes, e nem mesmo se tem conhecimento acerca das possibilidades de fazê-lo, tendo em vista a enorme população de quase 750 mil presos no Brasil ${ }^{5}$.

No que tange à possibilidade de Habeas Corpus enquanto substitutivo de recurso ordinário, a matéria também é controversa. Segundo a redação da Lex Matter, em seus artigos 102 e 105, incisos II, alíneas "a", contra o indeferimento da ação de HC cabe recurso ordinário. Pela redação ipsis litteris do mandamento constitucional, uma vez que a DPU já havia impetrado o writ na origem perante o TRF3, com pedido liminar idêntico, o qual fora negado (negou-se a liminar, não o mérito), esta deveria recorrer da decisão através de instituto recursal próprio. Contrariamente, em meados do ano de 2018, o Supremo Tribunal Federal passou a admitir a impetração originária em caráter substitutiva de recurso ordinário ${ }^{6}$, entretanto, as turmas do Superior Tribunal de Justiça decidem de maneira divergente.

Outrossim, aliado ao entendimento já sumulado, o posicionamento majoritário da doutrina também se alicerça no sentido de não ser possível manejar a mencionada ação constitucional contra decisão de Relator que, em Habeas Corpus requerido a Tribunal Superior, indefere a liminar, nos termos da súmula 691 do Supremo Tribunal Federal, a não ser que se demonstre flagrante ilegalidade ${ }^{7}$. Para Bernardo Gonçalves, o objetivo do enunciado "foi obstaculizar impetrações sucessivas do writ contra a não concessão de medida liminar" (FERNANDES, 2017, p. 671). Seguindo a mesma linha de intelecção, leciona Humberto Theodoro que "contra decisão proferida pelo Relator caberá agravo interno para o respectivo órgão colegiado" (THEODORO JÚNIOR, 2019, p.797). Portanto, in casu, vislumbra-se que, da decisão de indeferimento da liminar, proferida pelo Ministro Saldanha Palheiro, em sede de decisão monocrática, existe recurso interno para que o órgão de Defesa questione na própria Corte, submetendo a matéria a um órgão colegiado no âmbito do próprio Superior Tribunal de Justiça, do qual faz parte o Ministro Relator. Assim sendo, naquele momento processual seria desnecessária e inconcebível a apreciação pelo STF, pois ensejaria supressão de instância, tendo em vista a não superação da súmula 691 e, também, em virtude de meio recursal próprio na seara do STJ.

Em última análise, observa-se que a impetração do referido remédio constitucional enquanto

\footnotetext{
${ }^{6}$ (HC 152.752/PR, Relator: Ministro Edson Fachin, Tribunal Pleno, Data de Publicação: DJE 27/06/2018).

${ }^{7}$ De acordo com decisão do Min. Reynaldo Soares da Fonseca, da Quinta Turma do STJ, o impeditivo do enunciado 691 do STF só é ultrapassado se "a ilegalidade é tão flagrante que não escapa à pronta percepção do julgador (AgRg no HC 556.937/MG, Relator: Ministro Reynaldo Soares da Fonseca, Quinta Turma, Data de Julgamento: 20/02/2020, Data de Publicação: DJE 02/03/2020).
} 
substitutivo de recurso ordinário perante o STJ fora utilizado como mecanismo de estratégia e celeridade processual pela Defesa, tornando, em virtude da gravidade dos fatos narrados e da possível violação à saúde e à vida, o seu reconhecimento meramente possível, nos termos do entendimento do Supremo Tribunal Federal. No entanto, é oportuno salientar, também, que mesmo diante da importância da matéria discutida, estando o Brasil enfrentando a situação pandêmica de uma doença pouco conhecida e que se mostrou bastante grave e letal, principalmente em virtude do Estado de Coisas Inconstitucional declarado pelo STF, que torna os fatos narrados no pedido da DPU ainda mais delicados, a decisão do Ministro Saldanha Palheiro também foi consoante aos entendimentos da Corte Superior e da doutrina majoritária, uma vez que o pleito liminar já havia sido indeferido pelo Tribunal a quo, qual seja o TRF3, não sendo possível a análise do suposto constrangimento ilegal, sob pena de incorrer em supressão de instância. Igualmente, diante da impossibilidade do STF em reconhecer Habeas Corpus impetrado ante decisão de Relator de Tribunal Superior que indefere a liminar, sem a comprovada e evidente ilegalidade, nos termos da súmula 691, caberia ao Ministro, caso julgasse correto, conceder ex officio, podendo essa decisão fazê-lo incorrer nas problemáticas supracitadas, como a dificuldade de se cumprir o princípio da individualização da pena, dada a quantidade elevada de pessoas privadas de liberdade no país.

\section{REFERÊNCIAS BIBLIOGRÁFICAS:}

BRASIL. Constituição da República Federativa do Brasil de 1988, de 05 de outubro de 1988. Brasília: P residên cia d a R e públi c a d o B rasil, 1988 . D i s poníve 1 e m : http://www.planalto.gov.br/ccivil_03/constituicao/constituicao.htm. Acessado em: 10 de out. 2020.

. Superior Tribunal de Justiça. Habeas Corpus n 570.440/DF. Relator: Ministro Antônio Saldanha Palheiro. Processos do STJ, Brasília, 06 de março de 2020. Disponível em: https://processo.stj.jus.br/processo/revista/documento/mediado/?componente=MON\&sequencial $=108312$ 300\&tipo_documento=documento\&num_registro=202000791740\&data $=20200406 \&$ formato=PDF. Acesso em: 01 de out. 2020.

- Ministério da Justiça e Segurança Pública. Levantamento Nacional de Informações Penitenciárias: período de julho a dezembro de 2019. Disponível em: http://antigo.depen.gov.br/DEPEN/depen/sisdepen/infopen/infopen. Acesso em: 16 de out. 2020.

FERNANDES, Bernardo Gonçalves. Curso de Direito Constitucional / Bernardo Gonçalves Fernandes - 9. ed. rev. ampl. e atual. - Salvador. JusPODIVM, 2017.

SILVA, José Afonso da. Curso de Direito Constitucional Positivo. $22^{\circ}$ edição. 2002. São Paulo. Malheiros.

THEODORO JÚNIOR, Humberto. Curso de Direito Processual Civil, volume 3 / Humberto Theodoro Júnior. -52. ed. - Rio de Janeiro: Forense, 2019. 